Stručni članak

DOI 10.54478/ers.30.43.3

\title{
ANALIZA MOTIVACIJE UČENIKA U PROJEKTU ŠKOLSKE LIGE
}

Iva Suden ${ }^{1}$

${ }^{1}$ Srednja škola dr. Antuna Barca Crikvenica

\begin{abstract}
Sažetak
Suočeni s problemima održavanja nastave u vrijeme pandemije COVID-19 traženi su načini za poboljšanje tjelesne aktivnosti i motivacije učenika. Osmišljena je školska virtualna liga gdje su se učenici međusobno natjecali u četiri različita oblika kretanja: trčanje, hodanje, bicikl i rolanje. Tako smo motivirali učenike kako bi aktivnije provodili slobodno vrijeme. Svjesni činjenice da je ocjena često predmet motivacije pokušalo se promijeniti njihove stavove stvarajući im zanimljivo natjecanje.
\end{abstract}

Ključne riječi: pandemija, nastava, školska virtualna liga, hodanje, trčanje, vožnja bicikla, rolanje, motivacija

\section{Uvod}

Adolescenti u Hrvatskoj nedovoljno se kreću. Prema podacima Svjetske zdravstvene organizacije iz 2018. g. tjelesna aktivnost adolescenata opada s porastom dobi te je niža kod ženskoga spola. U dobi od 15 godina samo su 21,4\% učenika i 13\% učenica tjelesno aktivni 1 sat i više dnevno koliko se preporuča u toj dobi. Ipak, Hrvatska je među 10 zemalja s najvećom razinom tjelesne aktivnosti učenika. Pri usporedbi hrvatskih učenica i učenika s vršnjacima iz ostalih 45 zemalja uključenih u HBSC istraživanje Hrvatska je i 2018. godine u trećini zemalja s najvišom razinom tjelesne aktivnosti. Preporuka je Svjetske zdravstvene organizacije za djecu i mlade najmanje 60 minuta pa do nekoliko sati tjelesne aktivnosti umjerenoga do visokog intenziteta dnevno. Ograničenja kao što su zabrana održavanja treninga i natjecanja za mlađe dobne kategorije koje je doživio sport reflektirala su se i na nastavu TZK gdje učenici nisu smjeli sudjelovati u momčadskim igrama koje su inače motivirajuće i najlakše provedive $u$ nastavi. Različiti nastavnici imali su drukčiji pristup i materijalne uvjete za izvođenje nastave. Nastavnici TZK Srednje škole dr. Antuna Barca Crikvenica izradili su projekt školske virtualne lige gdje su se učenici tijekom studenog/ prosinca, veljače/ožujka te travnja/svibnja natjecali u četiri različita oblika kretanja: hodanje, trčanje, biciklizam i rolanje. Cilj Školske lige bio je dodatno potaknuti učenike na kretanje kroz natjecanje i utjecati na stvaranje navike bavljenja tjelesnim aktivnostima u slobodno vrijeme koje su bile ograničene zbog pandemije COVID-19.

\section{Cilj}

Cilj je ovoga rada utvrditi razinu i vrstu motivacije učenika aktivnostima koje se provode $u$ školskoj virtualnoj ligi (hodanje, trčanje, bicikl i rolanje) te utjecaj lige na daljnju tjelesnu aktivnost učenika.

\section{Metode rada}

\subsection{Uzorak ispitanika}

Ovom anketom obuhvaćeno je 120 učenika iz triju različitih škola u dobi od 15 do 18 godina: Srednje škole dr. Antuna Barca (gimnazijski smjer), Prve sušačke hrvatske gimnazije u Rijeci (gimnazijski smjer) te učenika Medicinske škole u Rijeci (medicinski tehničari) koji su u 
razdoblju od 1. travnja 2021. do 15. svibnja 2021. sudjelovali u projektu školske virtualne lige. U upitniku se nastojalo uočiti razlike u aktivnostima prije pandemije i za vrijeme školske lige te detektirati motive zbog kojih su se učenici uključili u ovaj projekt.

\subsection{Mjerni instrumenti}

Istraživanje je provedeno korištenjem prilagođenoga anketnog upitnika s motivima koji su smatrani važnima za nastavu TZK, a učenici su ih ispunili u digitalnom obliku (Microsoft Forms). Skala procjene imala je 5 stupnjeva: od 1- nikako se ne slažem do 5 - u potpunosti se slažem.

\subsection{Metode obrade podataka}

$\mathrm{U}$ analizi podataka korištena je deskriptivna statistika, tj. aritmetička sredina (Microsoft Excel) te tablice frekvencije odgovora ispitanika.

\section{Rezultati}

U anketi je sudjelovao nešto veći postotak učenika muškoga spola (59\%) od učenika ženskoga spola (41\%), a najveći je broj učenika bio u dobi od 15 godina (59\%). Postotak učenika koji treniraju neki sport nešto je veći od učenika koji se ne bave sportom (51\%), s tim da se 4\% učenika izjasnilo da zbog mjera ne treniraju. Učenici su svoju tjelesnu aktivnost prije pandemije COVID-19 procijenili visokom: $51 \%$ djece tjelesno je aktivno više od tri puta tjedno.

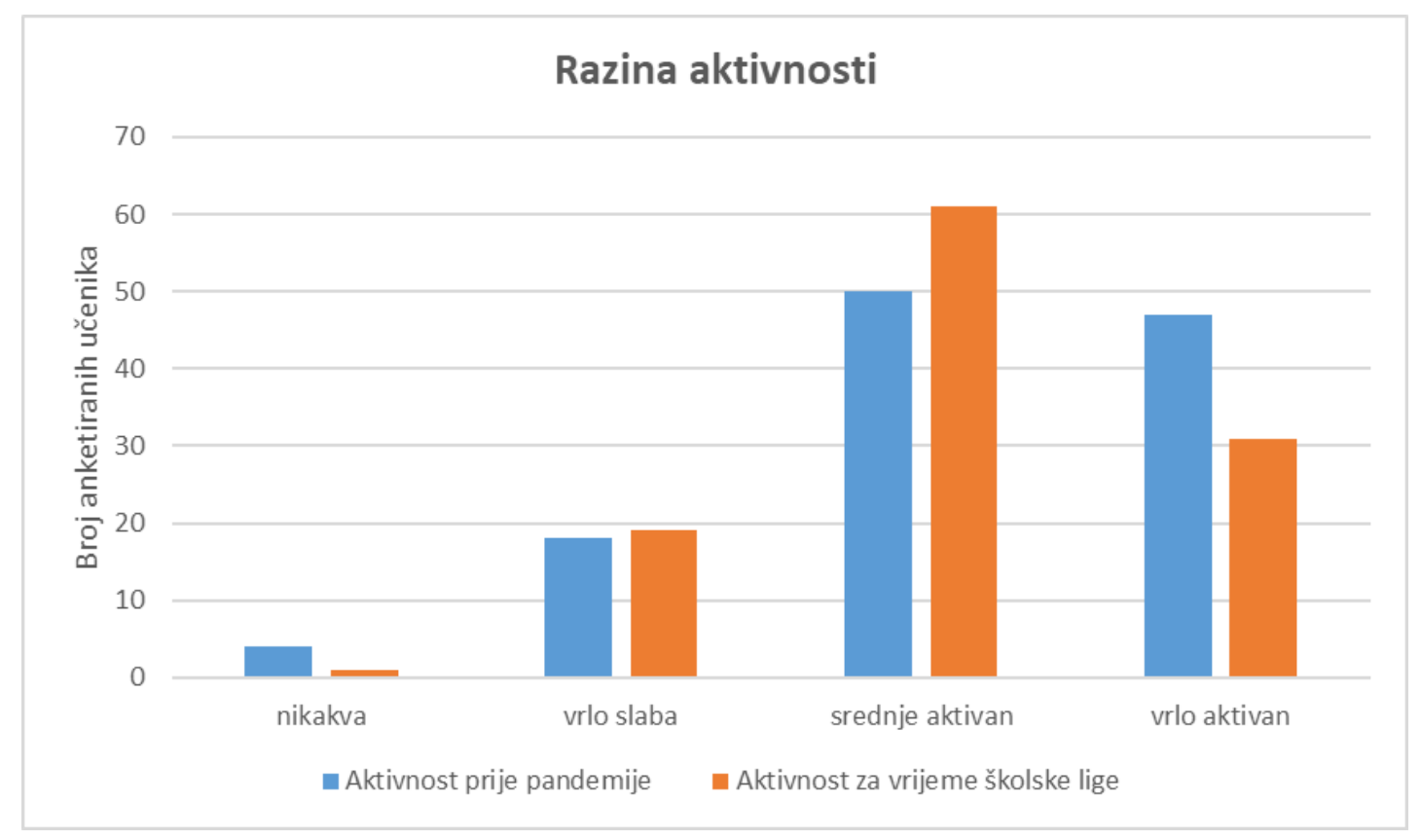

Slika 1. Razina aktivnosti prije pandemije i za vrijeme školske lige

Učenici su svoju tjelesnu aktivnost prije i nakon pandemije procijenili uglavnom ,srednje aktivno" te ipak postoji više aktivnih učenika od onih koji su svoju aktivnost procijenili sa „nikakva“ (Slika 1.). 


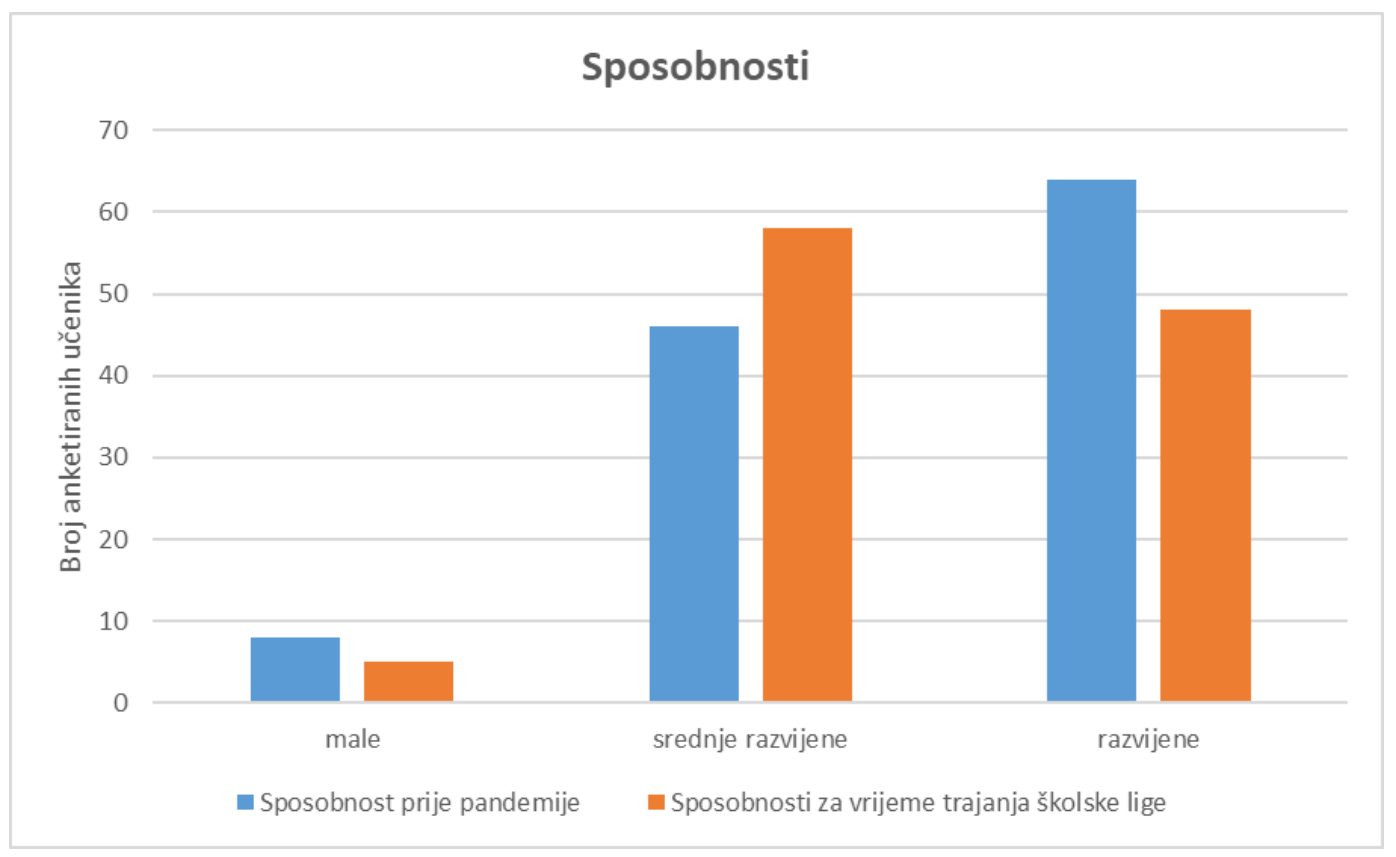

Slika 2. Sposobnosti učenika prije pandemije i za vrijeme školske lige

Sposobnosti učenika po njihovoj slobodnoj procjeni manje su razvijene za vrijeme trajanja školske lige nego prije pandemije (Slika 2.).

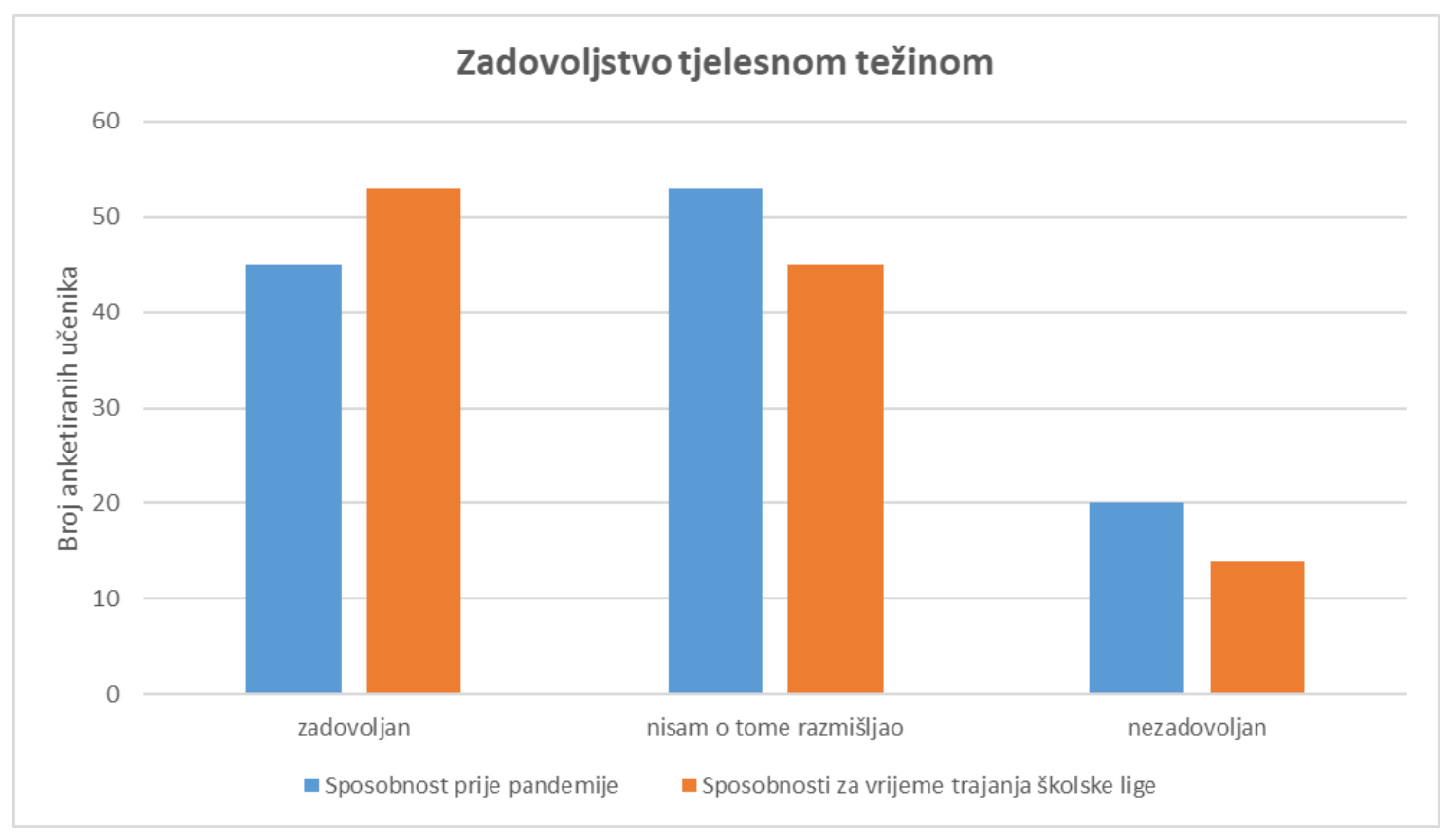

Slika 3. Zadovoljstvo tjelesnom težinom za vrijeme pandemije i školske lige

Istraživanje je pokazalo da je veći broj učenika zadovoljan ili nije o tome razmišljao od onih koji su nezadovoljni sa svojom težinom. 


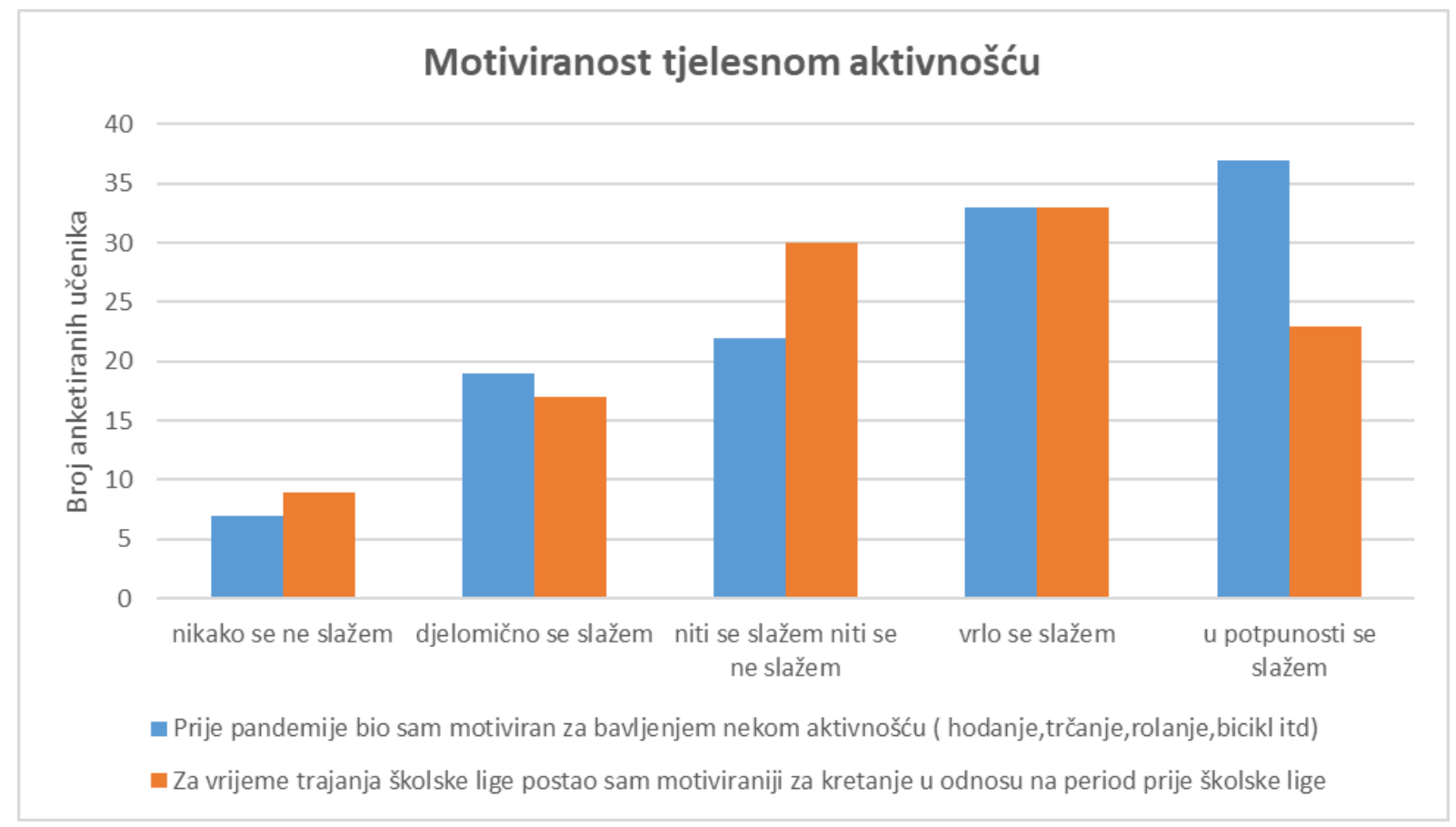

Slika 4. Motiviranost tjelesnom aktivnošću prije i za vrijeme pandemije

Na slici 4. vidljivo je da su za vrijeme trajanja školske lige učenici bili manje motivirani za bavljenje nekom aktivnošću u odnosu na motivaciju za kretanjem u vrijeme prije pandemije. Pretpostavka je da su učenici, tijekom ograničenja kretanja nužnih u vrijeme pandemije, osjetili da se manje kreću i da provode više vremena pred ekranima.

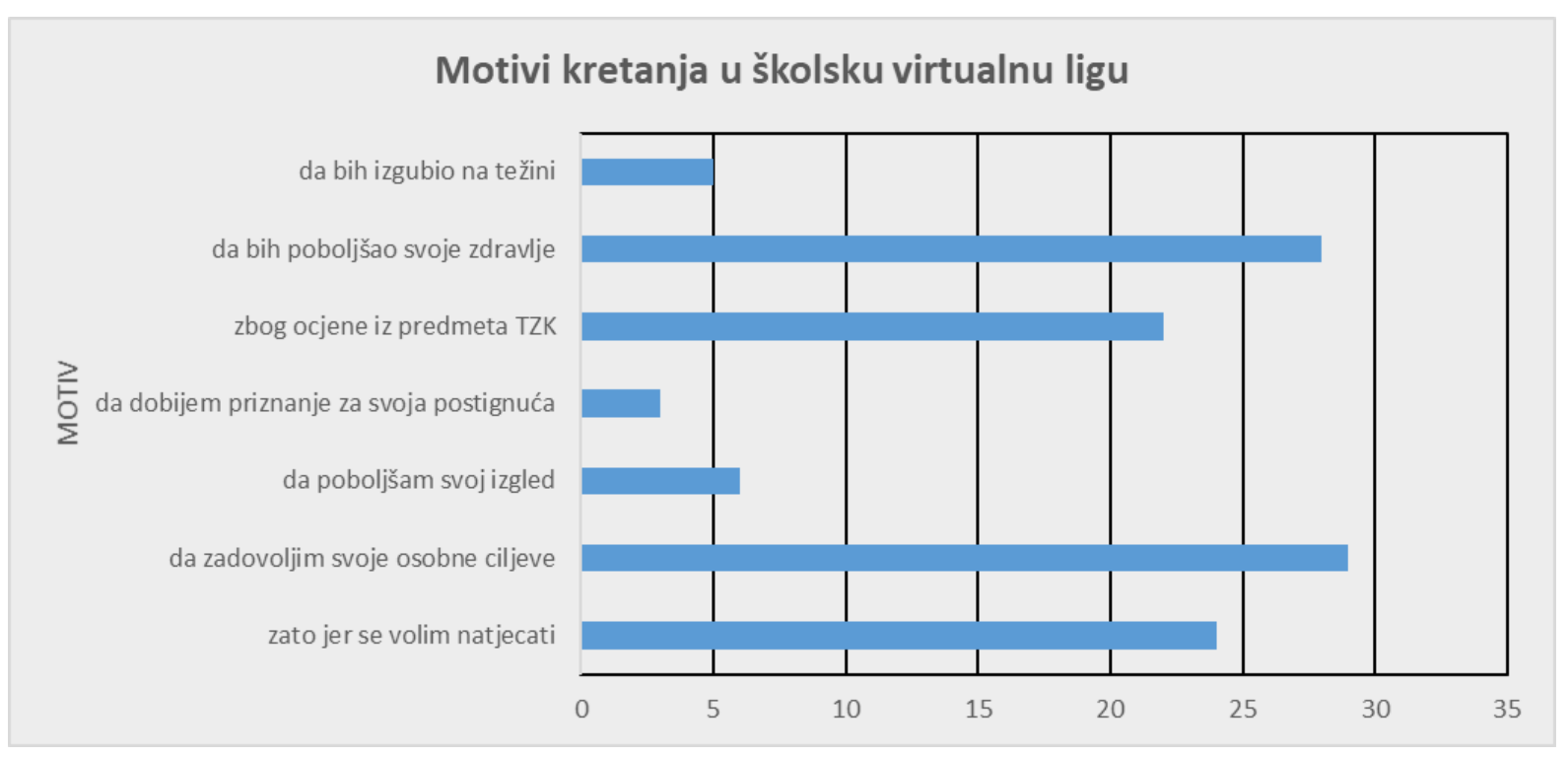

Slika 5. Motivi kretanja u školsku virtualnu ligu

Učenici su od ponuđenih motiva kretanja u školskoj ligi izdvojili zadovoljenje svojih osobnih ciljeva, poboljšanje zdravlja, želju za natjecanjem i ocjenu iz predmeta TZK kao prevladavajuće motive. 


\section{Diskusija}

Za vrijeme trajanja školske lige porasla je umjerena razina aktivnosti kod učenika, a smanjila se intenzivna aktivnost, što je objašnjeno time da je u tom razdoblju aktivna bila zabrana treniranja sportova na zatvorenom, pa je veći broj učenika sportaša smanjio svoju aktivnost dok je projekt školske lige kod učenika koji ne treniraju neki sport podignuo razinu aktivnosti od slabe do umjerene. Takvi rezultati istraživanja vidljivi su i kod Karuc i sur. (2020) gdje su autori primijetili pozitivan pomak u razini aktivnosti adolescenata koji nisu prije bili aktivni u nekom sportu. Također smatramo da je spomenuta zabrana utjecala na samoprocjenu učeničkih sposobnosti u smislu da su učenici sportaši svoje sposobnosti za vrijeme projekta školske virtualne lige ocijenili manjima dok su učenici koji nisu sportaši svoje sposobnosti ocijenili boljima.

Prije pandemije učenici su bili motiviraniji za bavljenje nekom sportskom aktivnošću što se također može promatrati u kontekstu pada interesa za sportom učenika sportaša zbog nemogućnosti adekvatnih treninga.

Zanimljivo istraživanje proveli su De Meester i suradnici (2014) na uzorku od 1049 učenika koji su sudjelovali u izvannastavnim aktivnostima kao što je zamišljena i ova školska liga. Autori navode da se učenici koji ne sudjeluju u sportskim aktivnostima u klubovima uključuju u izvannastavne aktivnosti. Smatra se da su neki od razloga tome financijska sredstva (plaćanje članarine, troškovi prijevoza itd.). Ovi autori također zaključuju da učenici nisu motivirani ekstrinzičnim motivima da bi sudjelovali u takvim aktivnostima te da zbog svojih prevladavajućih intrinzičnih motiva imaju pozitivan stav prema ovakvim aktivnostima.

Učenici su zauzeli neutralan stav u pogledu toga je li ih školska liga potaknula da više vježbaju, međutim značajan postotak izjavljuje da im se svidio ovakav način kretanja i natjecanja (20,5\%), a slične rezultate u svojim istraživanjima dobili su Rus, Radu i Vanvu (2016) gdje su autori naveli visoki postotak ispitanika s motivima želje za natjecanjem i poboljšanjem zdravlja Kada se promatra isključivo motiviranost učenika ovim projektom, može se zaključiti da su u prednosti intrinzični motivi (zadovoljenje osobnih ciljeva $24,8 \%$, poboljšanje zdravlja $23,9 \%$ ) u odnosu na ekstrinzične (zato što se vole natjecati 20,5\% i zbog ocjene iz predmeta TZK 18,8\% što je slično rezultatima koje su dobili Kilpatric,Hebert i Bartolomew (2005), odnosno gdje su rezultati autora pokazali da su učenici motivirani više intrinzičnim nego ekstrinzičnim motivima.

$\mathrm{U}$ istraživanju motivacije na brazilskim sportašima do $18 \mathrm{~g}$. dobiveni rezultati pokazuju da su sportaši motivirani željom za samoostvarenjem i dominacijom u sportu (Guedes i Netto, 2013) što je oprečno rezultatima ovoga istraživanja.

Svakako treba istaknuti da se velika većina učenika (95\%) opredijelila da će i dalje nastaviti s kretanjem bez obzira na završetak školske lige.

\section{Zaključak}

Projekt školske lige opravdao je naša očekivanja i aktivirao učenike koji nisu aktivni u nekom sportu. Motivacija je intrinzična što je također pozitivno s obzirom na to da je projekt školski pa je bilo očekivano da će učenici biti motivirani vanjskim motivima, tj. ocjenom iz predmeta TZK. Iako je pandemija „usporila“ sport općenito, možemo zaključiti da je možda donijela i pozitivan pomak u rekreativnom sportu. 


\section{Literatura}

1. De Meester, A., Aelterman, N., Cardon, G., De Bourdeaudhuij, I., \& Haerens, L. (2014). Extracurricular school-based sports as a motivating vehicle for sports participation in youth: a cross-sectional study. The international journal of behavioral nutrition and physical activity, 11, 48. https://doi.org/10.1186/1479-5868-11-48

2. Guedes, D. P., \& Netto, J. E. (2013). Sport participation motives of young Brazilian athletes. Perceptual and motor skills, 117(3), 742-759. https://doi.org/10.2466/06.30.PMS.117x33z2

3. Karuc, J., Sorić, M., Radman, I. \& Mišigoj-Duraković, M. (2020) Moderators of Change in Physical Activity Levels during Restrictions Due to COVID-19 Pandemic in Young Urban Adults. Sustainability, 12 (16), 6392, 10 doi:10.3390/su12166392

4. Kilpatrick, M., Hebert, E., \& Bartholomew, J. (2005). College students' motivation for physical activity: differentiating men's and women's motives for sport participation and exercise. Journal of American college health : J of ACH, 54(2), 87-94. https://doi.org/10.3200/JACH.54.2.87-94

5. Rus, C.M., Radu, L.E., Vanvu, G.I. (2016). Motivation for participating to sports competitions in school. Revista de Cercetare si Interventie Sociala, 52 (MARCH), pp. 195-203.

6. World Health Organization. Croatia - Physical activity factsheet; Preuzeto 23. ožujka 2021. https://www.euro.who.int/ en/health-topics/disease-prevention/physicalactivity/data-and-statistics/physical-activity-fact-sheets/physical-activi[1]ty-countryfactsheets/croatia. Datum pristupa 23. ožujka 2021.

\section{Prilog: Anketni upitnik}

\begin{tabular}{|c|c|}
\hline 1. & Navedi svoje godine i spol. \\
\hline 2. & Treniraš li aktivno neki sport? \\
\hline 3. & $\begin{array}{l}\text { Prije COVID-19 pandemije bio sam aktivan: } \\
\text { - jednom tjednom, } \\
\text { - } 2-3 \text { puta, } \\
\text { - } \quad \text { više puta tjedno }\end{array}$ \\
\hline 4. & $\begin{array}{l}\text { Ocijeni razinu svoje aktivnosti prije pandemije i za vrijeme školske lige: } \\
\text { - nikakva, } \\
\text { - vrlo slaba, } \\
\text { - srednje aktivan, } \\
\text { - vrlo aktivan }\end{array}$ \\
\hline 5. & $\begin{array}{l}\text { Ocijeni razinu svojih sposobnosti prije pandemije i za vrijeme trajanja školske lige: } \\
\text { - male, } \\
\text { - srednje razvijene, } \\
\text { - razvijene }\end{array}$ \\
\hline 6. & $\begin{array}{l}\text { Zadovoljstvo težinom i izgledom prije pandemije i za vrijeme trajanja školske lige: } \\
\text { - zadovoljan, } \\
\text { - nisam o tome razmišljao, } \\
\text { - nezadovoljan }\end{array}$ \\
\hline
\end{tabular}




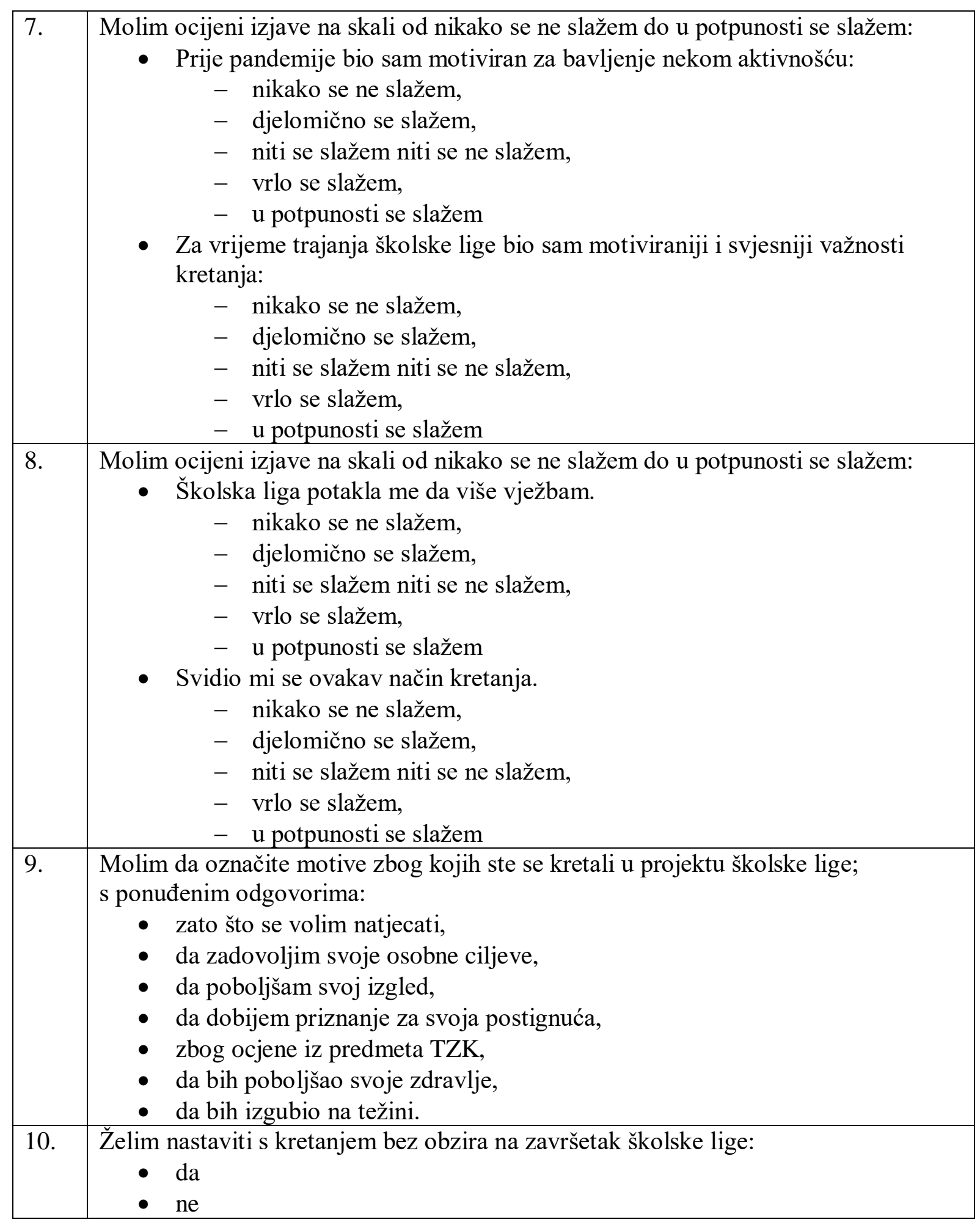

